\title{
Corneal aldehyde dehydrogenase and glutathione S-transferase activity after excimer laser keratectomy in guinea pigs
}

\author{
Kamil Bilgihan, Ayse Bilgihan, Berati Hasanreisoğlu, Nurten Turkozkan
}

\begin{abstract}
Background-The free radical balance of the eye may be changed by excimer laser keratectomy. Previous studies have demonstrated that excimer laser keratectomy increases the corneal temperature, decreases the superoxide dismutase activity of the aqueous, and induces lipid peroxidation in the superficial corneal stroma. Aldehyde dehydrogenase (ALDH) and glutathione S-transferase (GST) are known to play an important role in corneal metabolism, particularly in detoxification of aldehydes, which are generated from free radical reactions.

Methods-In three groups of guinea pigs mechanical corneal de-epithelialisation was performed in group I, superficial corneal photoablation in group II, and deep corneal photoablation in group III, and the corneal ALDH and GST activities measured after 48 hours.

Results-The mean ALDH and GST activities of group I and II showed no differences compared with the controls $(p>0.05)$. The corneal ALDH activities were found to be significantly decreased $(p<0.05)$ and GST activities increased $(\mathbf{p}<0.05)$ in group III.

Conclusion-These results suggest that excimer laser treatment of high myopia may change the ALDH and GST activities, metabolism, and free radical balance of the cornea.
\end{abstract}

(Br f Ophthalmol 1998;82:300-302)

Excimer laser emits ultraviolet (UV) radiation at $193 \mathrm{~nm}$ and causes a photochemical reaction that results in an ablation of the corneal tissue. UV light is also known to induce apoptosis in many cells. Excimer laser photoablation increases the temperature of the cornea and decreases the superoxide dismutase (SOD) activity of the aqueous humour. ${ }^{12}$ These findings indicate that there have been some changes in the free radical balance of the aqueous humour after excimer laser photoablation. $^{2}$ The rise of the corneal temperature during excimer laser photoablation does not cause degeneration of the collagen fibres but induces some damage in the ground substance. ${ }^{1}$ Thermal degradation of organic materials may produce homolytic fission and liberate toxic oxygen radicals. ${ }^{3}$

Free oxygen radicals can induce peroxidation of fatty acids or lipid cell membranes, known as lipid peroxidation, and lead to oxida- tive tissue damage. ${ }^{3}$ Products of lipid peroxidation consist of hydroperoxides, conjugated diens, malondialdehyde and other cytotoxic aldehydes.

Corneal aldehyde dehydrogenase (ALDH) is the major soluble protein of the mammalian cornea and it has an important role in detoxification of cytotoxic aldehydes. ${ }^{45}$ Corneal glutathione S-transferase (GST) degrades xenobiotic agents and protects cellular membrane integrity. ${ }^{6-8}$ GST mediates a pathway alternative to ALDH for aldehyde detoxification. ${ }^{8}$ These two enzymes play an important role in the defence mechanism against cytotoxic aldehydes that are generated in the cells after membrane lipid peroxidation.

It is known that corneal epithelial removal induces morphological changes in the keratocyte population and this loss of keratocytes is not associated with the method of de-epithelialisation. ${ }^{9}$ Corneal de-epithelialisation and UV light from the excimer laser may be the causes of keratocyte loss after photorefractive keratectomy (PRK). ${ }^{10}$

In the present study, the effects of corneal de-epithelialisation and the depth of the corneal photoablation on ALDH and GST activities of the corneal tissue were investigated in guinea pigs.

\section{Material and methods}

Twenty seven albino guinea pigs were used in the study. Institutional guidelines regarding animal experimentation were followed and only one eye of each animal was used in the study. Anaesthesia was induced by an intramuscular injection of $25 \mathrm{mg} / \mathrm{kg}$ ketamine hydrochloride injection, and topical proxymetacaine (proparacaine) hydrochloride.

Corneal ALDH and GST activities were measured in four groups. The control group consists of 18 eyes of nine animals. The corneal epithelium was removed with a blunt spatula (Visitec, Sarasota, USA) in group I, II, and III. We performed $10 \mu \mathrm{m}$ corneal photoablation in group II (nine eyes), and $40 \mu \mathrm{m}$ corneal photoablation in group III (nine eyes) after deepithelialisation.

The eyes were irradiated with $193 \mathrm{~nm}$ excimer laser (MEL 60, Aesculap-Meditec, Heroldsberg, Germany) under in vivo conditions. The energy at the cornea was 220 $\mathrm{mJ} / \mathrm{cm}^{2}$, with a firing rate of $20 \mathrm{~Hz}$, and diameter of ablation zone was $4 \mathrm{~mm}$.

Animals were killed 48 hours after photoablation, the central corneal tissue was removed by using a $4 \mathrm{~mm}$ trephine and homogenised in 


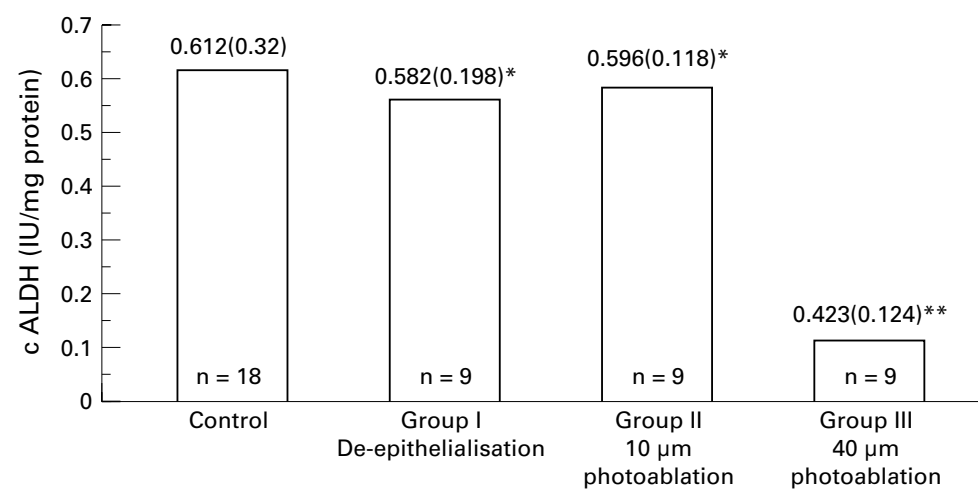

Figure 1 Corneal aldehyde dehydrogenase (c ALDH) activities of the groups (mean (SD)). ${ }^{\star} p>0.05,{ }^{\star \star} p<0.05$, significantly different from controls. Student's $t$ test was used.

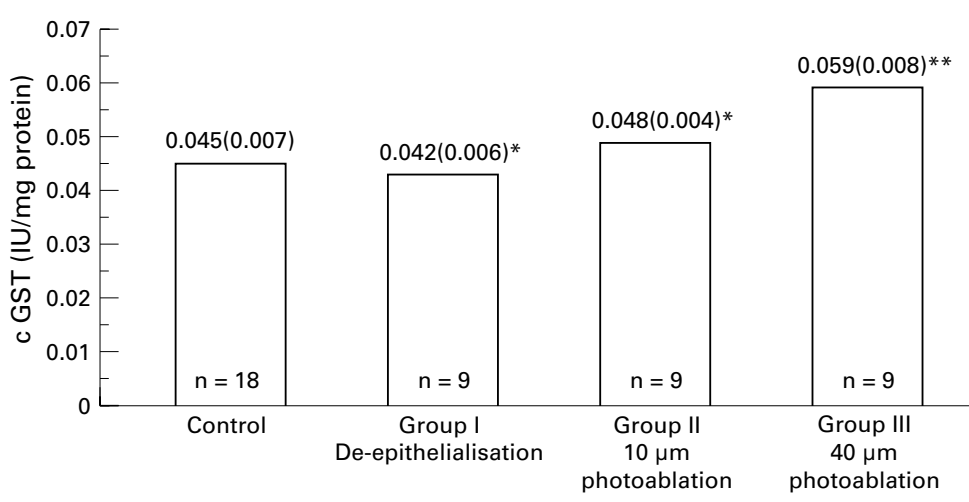

Figure 2 Corneal glutathione $S$-transferase (c GST) activities of the groups (mean (SD)). ${ }^{\star} p>0.05,{ }^{\star} p<0.05$, significantly different from control. Student's $t$ test was used.

$0.1 \mathrm{M}$ TRIS- $\mathrm{HCl}$ buffer, $\mathrm{pH}$ 7.2, containing $154 \mathrm{mM} \mathrm{NaCl}$ on melting ice using a glass homogeniser. Particulate material was pelleted by centrifugation at $3000 \mathrm{~g}$ for 20 minutes at $4^{\circ} \mathrm{C}$. Corneal ALDH, GST activities, and the protein concentrations were measured in the supernatant. The protein concentration was measured using the Lowry method with bovine serum albumin as a standard. ${ }^{11}$

\section{ALDH ASSAY}

The assay was performed by incubating $10 \mu \mathrm{l}$ of supernatant in $1 \mathrm{ml}$ of substrate solution (0.1 M TRIS-HCl $\mathrm{pH} 8.5 ; 1 \mathrm{mM}$ NADP and added in $50 \mu \mathrm{l}$ methanolic solution of $10 \mathrm{mM}$ benzaldehyde). In a spectrophotometer at $30^{\circ} \mathrm{C}$, the reduction of NADP to NADPH was followed for 3 minutes at $340 \mathrm{~nm}$. Correction for the blank reaction was done using a reference cuvette containing substrate alone. Enzyme activity was expressed in international units (IU) per milligram of protein; 1 IU of enzyme activity represents the amount that catalyses the transformation of $1 \mu \mathrm{mol}$ of substrate per minute. ${ }^{12}$

GST ASSAY

GST activity was determined according to the method of Habig et al. ${ }^{13}$ The assay mixture (1 $\mathrm{ml})$ contained $1 \mathrm{mM}$ 1-chloro-2,4dinitrobenzene and $1 \mathrm{mM}$ GSH in $0.1 \mathrm{M}$ potassium phosphate buffer, $\mathrm{pH}$ 6.5. After adding $10 \mu \mathrm{l}$ corneal extract, the rate of increased absorption was measured at $340 \mathrm{~nm}$ for 3 minutes at $25^{\circ} \mathrm{C}$. The enzyme activity was expressed in IU/mg of protein.

Results were analysed by Student's $t$ test.

\section{Results}

The mean corneal ALDH activities and the statistical analyses are shown in Figure 1 and GST activities in Figure 2.

Corneal ALDH and GST activities of groups I and II showed no significant difference compared with the control group $(p>0.05)$. The ALDH activity of group III decreased significantly when compared with the control group $(p<0.05)$. The mean corneal GST activity of group III was higher than the control group $(\mathrm{p}<0.05)$.

\section{Discussion}

It is believed that UV light from the excimer laser and corneal de-epithelialisation may be the causes of keratocyte loss (mediated by apoptosis) after PRK. ${ }^{14}$ Excimer laser photoablation increases the corneal temperature during PRK and decreases the SOD activity of the aqueous humour. ${ }^{2}$ A recent study has demonstrated the presence of oxygen radical mediated tissue damage in the form of lipid peroxidation following excimer laser keratectomy, and this lipid peroxidation could be from oxygen free radicals generated by the infiltrating polymorphonuclear cells at the site of tissue damage. ${ }^{15}$

The cornea protects itself from radical injury by antioxidant systems. ${ }^{16}$ When the production of free radicals is more than their detoxification, oxygen metabolites accumulate in the cornea, and initiate lipid peroxidation in biological membranes. ${ }^{16}{ }^{17}$ Toxic aldehydes are the products of membrane lipid peroxidation. ${ }^{18}$

Corneal ALDH is the major soluble protein of the cornea, the high level of this protein in the cornea suggests a vital role in corneal metabolism, particularly in detoxification of aldehydes, which are generated from membrane lipid peroxidation. ${ }^{19}$ Based on the gene sharing phenomenon and parallel between corneal transparency and the appearance of the $54 \mathrm{kDa}$ protein during embryonal development, it has also been suggested that the corneal ALDH may play a structural role in the cornea. ${ }^{8}$ In previous studies corneal ALDH activities were found to be decreased in pathological corneas (for example, graft rejection and keratoconus), and the depletion in ALDH activity was explained by decreased ALDH content or decrease of the normal enzymatic activity related to the conformational shift. ${ }^{19}$ In our study ALDH activity did not change in groups I and II, but significantly decreased in group III. These findings suggest that the depth of the corneal photoablation is an important factor which could change the corneal ALDH activity. The depletion in ALDH activity after deep corneal photoablation may be explained by a decrease of the normal enzymatic activity related to the conformational shift.

In another study we found a positive correlation between the depth of corneal photoablation and aqueous TGF-BI concentration. ${ }^{20}$ This finding also supports the theory that the dose of the excimer laser energy is an 
important factor which may change the corneal wound healing response. Although there is an individual variation in corneal wound healing, corneal haze and myopic regression are frequently seen after treatment of high myopia and it is believed that extensive stromal wound healing is the reason for these complications. $^{21}$

It is reported that toxic aldehyde products of lipid peroxidation are natural substrates for GST. $^{22}$ Consequently, a major biological function of GST may be to protect the cell from these toxic compounds originating in oxygen metabolism. GST activities were found to be increased in some corneal disorders (for example, herpetic keratitis, keratoconus, and graft rejection). ${ }^{8}$ The assumption of the authors for this outcome was an increased peroxidase pathway, possibly promoted by reduced glutathione production, derived from the hexose monophosphate shunt. ${ }^{8}$ In our study GST activity in group III showed similar changes to some pathological corneas, but the GST activities of groups I and II did not change.

ALDH and GST activities of groups I and II showed no significant difference compared with the control group $(p>0.05)$. These findings suggest that mechanical deepithelialisation and superficial corneal photoablation may not change the corneal ALDH and GST activities.

Many surgeons believe that PRK is a safe and predictable procedure in low and moderate myopia; in a clinical series the refractive outcome was more accurate and predictable after superficially performed PRK. ${ }^{21}$ Corneal scarring after PRK is significantly correlated with the attempted correction. ${ }^{23}$ In our study, corneal ALDH and GST showed distinctive behaviour in group III. It is interesting that ALDH and GST activities of deeply photoablated corneal samples showed similar changes to some pathological corneas.

The surgical outcome of PRK depends on the healing response of the cornea. The action of extracellular matrix proteins, growth factors, cytokines, and free radical damage influence corneal wound healing. ${ }^{2101520}$ Furthermore, the dose of the excimer laser energy may change the corneal wound healing response. In a previous study we have demonstrated that there is a positive correlation between the depth of corneal photoablation and aqueous TGF-BI concentration..$^{20}$ In the present investigation, we found that the dose of the excimer energy may change the corneal ALDH and GST activities. These findings support the theory that PRK treatment of high myopia induces a greater healing response in the cornea, by inducing the secretion of growth factors and changing corneal enzyme activity. ${ }^{21}$

In conclusion, excimer laser treatment of low and moderate myopia may be safer than with high myopia. We are getting acceptable clinical results with PRK, especially in low myopia, but we need further investigation on the regulatory mechanisms of corneal wound healing.

1 Niizuma T, Ito S, Hayashi M, et al. Cooling the cornea to prevent side effects of photorefractive keratectomy. $\mathcal{F}$ Refract Corneal Surg 1994;10:262-6.

2 Bilgihan K, Bilgihan A, Akata F, Türközkan N, Hasanreisoğlu B. Excimer laser corneal surgery and free oxygen radicals. fpn f Ophthalmol 1996;40:154-7.

3 Basaga HS. Biochemical aspects of free oxidatives. Biochem Cell Biol 1990;68:989-98.

4 Abedinia M, Pain T, Algar EM, Holmes RS. Bovine corneal aldehyde dehydrogenase. The major soluble corneal protein with a possible dual protective role for the eye. Exp protein with a possible du.
Eye Res 1990;51:419-26.

5 Gondhowiardjo TD, van Haeringen NJ, Völker-Dieben HJ, t al. Analysis of corneal aldehyde dehydrogenase patterns in pathologic corneas. Cornea 1993;12:146-54

6 Singh SV, Hong TD, Srivastava SK, Awasthi YC. Characterization of glutathione S-transferases of human cornea. Exp Eye Res 1985;40:431-7.

7 Saneto RP, Awasthi YC, Srivastava SK. Mercapturic acid pathway enzymes in bovine ocular lens, cornea, retina and retinal pigmented epithelium. Exp Eye Res 1982;35:10711.

8 Gondhowiardjo TD, van Haeringen NJ. Corneal aldehyde dehydrogenase, glutathione reductase and glutathione S-transferase in pathologic corneas. Cornea 1993;12: $310-4$.

9 Campos M, Raman S, Lee M, Mc Donnell PJ. Keratocyte loss after different methods of de-epithelialization. Ophthalmology 1994;101:890-4.

10 Nishida T, Tanaka T. Extracellular matrix and growth factors in corneal wound healing. Curr Opin Ophthalmol 1996;7:2-11.

11 Lowry OH, Rosebrough NJ, Farr AJ, Randall RJ. Protein measurement with folin phenol reagent. F Biol Chem 1951; 193:265-6.

12 Finnerty WR. Aldehyde dehydrogenases from acinetobacter. Methods Enzymol 1990;188:18-21.

13 Habig WH, Pabst MJ, Jakoby WB. Glutathione S-transferases: the first enzymatic step in mercapturic acid formation. F Biol Chem 1974;249:130-9.

14 Wilson SE, He YG, Weng J, et al. Epithelial injury induces keratocyte apoptosis: hypothesized role for the interleukin-1 system in the modulation of corneal tissue interleukin-1 system in the modulation of corneal tissue organization

15 Hayashi S, Ishimoto S, Wu G, et al. Oxygen free radical damage in the cornea after excimer laser theraphy. $\mathrm{Br} \mathcal{F}$ Ophthalmol 1997;81:141-4.

16 Marak GE, Kozak Y, Faure JP. Free radicals and antioxidants in the pathogenesis of eye diseases. In: Emerit , ed. Antioxidants in therapy and preventive medicine. New York: Plenum Press, 1990:513-27.

17 Bhuyan KC, Bhuyan DC. Molecular mechanism of cataractogenesis. Toxic metabolites of oxygen as initiators of lipid peroxidation and cataract. Curr Eye Res 1984;3:67-81.

18 Lindahl R, Petersen DR. Lipid aldehyde oxidation as a physiological role for class 3 aldehyde dehydrogenases. Biochem Pharmacol 1991;41:1583-7.

19 Gondhowiardjo TD, van Haeringen NJ, Hoekzema R, Pels $\mathrm{K}$, Kijlstra A. Detection of aldehyde dehydrogenase in human corneal extracts. Curr Eye Res 1991;11: 1001-7.

20 Bilgihan K, Gürelik G, Okur H, et al. Aqueous TGF-BI levels of the rabbit eyes after excimer laser photoablation. els of the rabbit eyes after excin
Ophthalmologica 1997;211:380-3.

21 Epstein D, Fagerholm P, Nyström HH, Tengroth B. Twenty-four month follow up of excimer laser photorefractive keratectomy for myopia. Ophthalmology 1994;101: 1558-64.

22 Alin P, Danielson H, Mannervik B. 4-Hydroxyalk-2-enals are substrates for glutathione transferase. FEBS Lett 1985; 179:267-70

23 Seiler T. Refractive corneal surgery with lasers. Curr Opin Ophthalmol 1996;7:47-51. 